\title{
Removal of Solid Impurities from Coal Gasification Wastewater by Sand Filtration
}

\author{
Li Dai ${ }^{1}$ and Hualin Wang ${ }^{1, *}$ \\ ${ }^{1}$ National Engineering Laboratory for Industrial Wastewater Treatment, East China University of Science and Technology, Shanghai, \\ 200237, PR China
}

\begin{abstract}
Coal gasification wastewater has complex pollutant components and high COD value, and contains a variety of toxic and harmful substances. The treatment of coal gasification wastewater has always been one of the important problems in the development of coal gasification industry in China. In this paper, aiming at the removal of fine particle pollution in coal gasification wastewater, the sand filtration method was used to explore the changes of parameters such as solid content removal, separation accuracy, grade efficiency under the conditions of separating different bed thicknesses. With this separation method, the fine particle pollutants in coal gasification wastewater can be effectively removed by more than $95 \%$, the separation accuracy can reach $0.46 \mu \mathrm{m}$. The operation conditions are optimized for further industrial application.
\end{abstract}

\section{Introduction}

China's fossil energy structure is more coal and less oil. As the main mineral energy, coal has an important impact on China's industrial economic development[1]. In recent years, the rise of coal chemical industry has further improved the utilization value of coal and reduced China's dependence on petroleum resources. However, with the increase of environmental protection requirements, wastewater from coal gasification has gradually become a bottleneck restricting the development of coal chemical industry[1,2].

Coal gasification wastewater has complex pollutant components and high COD value, and contains a variety of toxic and harmful substances[1,3]. Coal gasification wastewater poses a threat to human health. If these wastewater are not treated effectively, it will lead to crop death and water pollution. At the same time, because some substances in coal gasification wastewater are difficult to be removed by biological means[4], it is environmentally persistent and will cause long-term harm to the ecological environment once discharged[1].The treatment of coal gasification wastewater has always been one of the important problems in the development of coal gasification industry in China. For coal gasification wastewater treatment, domestic and foreign researchers have carried out a lot of research work[5].

At present, the common remediation methods to deal with coal gasification wastewater contain physical, chemical and biological processes, namely adsorption by activated carbon[6] or clays[7], solvent extraction[8], liquid membrane[9], coagulation[10], bubble[11] wet air oxidation[12], ozonation[13], photocatalytic oxidation[14] and decomposition by Fenton reagents $[5,15]$. In order to deal with this kind of complex coal gasification wastewater with strong toxicity and low biodegradability, it often needs to adopt a variety of technologies for combined treatment[16]. Although effective, some of these techniques present a number of disadvantages[5]. Nowadays, the more feasible treatment process is to remove solid and oil, recover phenol and ammonia, biochemical treatment, advanced treatment, membrane treatment[17], evaporation[18] and crystallization[19], etc. However, before phenol ammonia recovery, coal gasification wastewater needs to be pretreated with solid removal. Now that separation process during industrial production accounts for $10-15 \%$ of the global energy consumption[20], it's urgent to develop a kind of separation method and process with high efficiency, high accuracy and low energy consumption for the removal of solid impurities in coal gasification wastewater.

Deep bed filtration is usually employed to remove fine and colloidal particulates from liquid suspensions[21]. When a diluted suspension flows through a filtering granular bed, the particles to be removed approach the filter grains (collectors) by various transport mechanisms (direct interception, inertia, sedimentation, molecular diffusion, electrostatic forces, hydrodynamic action) and they can further adhere to the collector surface (by van der Waals forces, electric double layer interactions, hydrogen bonding, mutual adsorption of polymeric species)[22]. Sand[23], anthracite coal, granular activated carbon[6], garnet, natural zeolites, synthetic inorganic sorbents, ion exchange resins, glass and expanded polystyrene beads, are common granular materials used to remove particles from a diluted suspension by deep bed filtration, and

* Corresponding author: wanghl@ecust.edu.cn 
rapid sand filtration is widely applied to water treatment[24].

In this study, a sand filtration method based on irregular medium was proposed, and a small test by the method was carried out to separate particle impurities from coal gasification wastewater. Through the indexes of solid content, separation efficiency, separation accuracy and classification efficiency in coal gasification wastewater, the solid content and separation efficiency of quartz sand bed under different bed thicknesses were investigated, and the feasibility of removing solid impurities in coal gasification wastewater by this separation method was evaluated. At the same time, using this method, the separation accuracy of solid impurities in coal gasification wastewater can reach $0.46 \mu \mathrm{m}$, which further verifies the feasibility of the separation method. The operating conditions of industrial application of this method were also optimized.

\section{Material and methods}

\subsection{Experimental equipment and setup}

The separator adopted in the experiment was made of Organic glass. The dimension of the separator was as shown in Fig. 1 and Table 1, i.e. the inner diameter D of the main part was $70 \mathrm{~mm}$, the length $\mathrm{H}$ of the cylinder was $12000 \mathrm{~mm}$, the head height h1 was $50 \mathrm{~mm}$, the pipe dimension $\mathrm{d}$ of the top of the head was $10 \mathrm{~mm}$, and the filling height $\mathrm{L}$ of the separator was different. The principal of the method is to use the bed piled up by quartz sand filtration medium $(1.5 \mathrm{~mm})$ to form a deep bed filtration.

The experimental process was shown in Figure 1. First, the coal gasification wastewater to be treated was poured into the sink, then the pump was started and the flow rate was adjusted. The coal gasification wastewater was separated by the separation bed, and after it runs stably for 2 minutes, it was sampled and marked at the outlet sampling port. In this experiment, the removal of fine solid impurities in coal gasification wastewater by separation bed was mainly investigated, and the feasibility of the separation process was also investigated. In the bed filtration process, particles were removed during the flow of asuspension through a granular bed (the top of bed, the middle of bed, the bottom of bed). It followed that if particles followed the fluid streamlines; many of them would never touched a grain surface and been removed from the flow. However, transport moved the particles across the streamlines, in such a way that they reached the immediate vicinity of a grain surface. When they arrived there, attachment can occur depended on the nature of the surface-particle interactions.

During the experiment, the flow velocity of coal gasification wastewater was adjusted $10 \mathrm{~m} / \mathrm{h}$ during the whole experiment process to match a rational ratio of industrial production and the test. After inlet properties of the experimental system held stable for over two minutes, Meanwhile, the effluent samples were taken, and was recorded respectively.

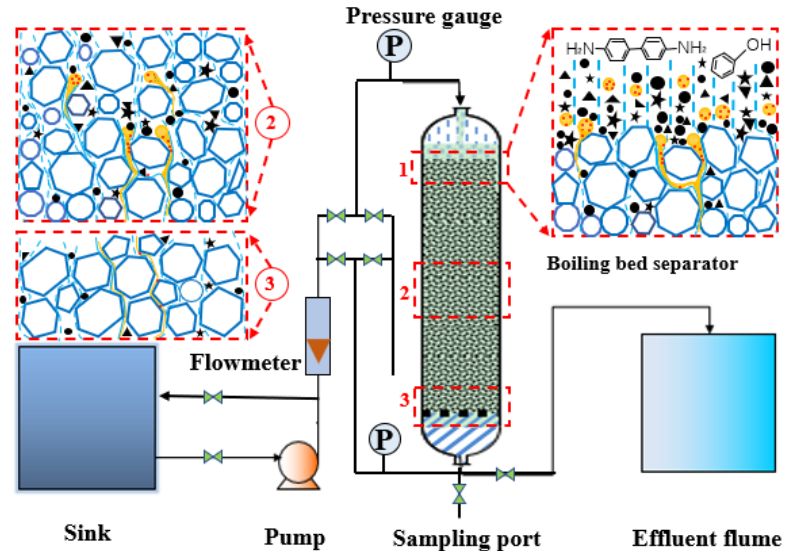

Fig. 1. Flow chart and principle diagram of coal gasification wastewater separation. (1) schematic diagram at top of bed; (2) schematic diagram at middle bed; (3) schematic diagram at bed bottom

Table 1. Structure parameters.

\begin{tabular}{|c|c|c|c|c|}
\hline $\begin{array}{c}D \\
(\mathrm{~mm})\end{array}$ & $\begin{array}{c}H \\
(\mathrm{~mm})\end{array}$ & $\begin{array}{c}L \\
(\mathrm{~m})\end{array}$ & $h_{l}(\mathrm{~mm})$ & $\begin{array}{c}d \\
(\mathrm{~mm})\end{array}$ \\
\hline 70 & 12000 & $\begin{array}{l}1.9 、 3.8 、 4.75 、 \\
5.7 、 7.6 、 9.5 、 11.4\end{array}$ & 50 & 10 \\
\hline
\end{tabular}

\subsection{Experimental material}

The coal gasification wastewater was produced by a coal chemical plant in Yunnan, China. The $\mathrm{pH}$ of the coal gasification wastewater was 9.2-9.4 and COD was about $34,000 \mathrm{mg} / \mathrm{L}$.

The particle size test of solid impurities in the coal gasification wastewater was shown in Figure 2 (a) and Fig. 2 (b). The $\mathrm{D}_{\mathrm{v}}(50)$ particle size of the solid impurities in the coal gasification wastewater was $7.98 \mu \mathrm{m}$ and the specific surface area was $1393 \mathrm{~m}^{2} / \mathrm{kg}$, of which $99 \%$ was in the waste liquid Fig. 2(c) was a scanning electron microscope of solid particles, from which it can be seen that the solid particles in the coal gasification wastewater were fine particles of different sizes, and the surface of the fine particles was rough, as shown in fig. 2(d), and there were more particles about one micron.

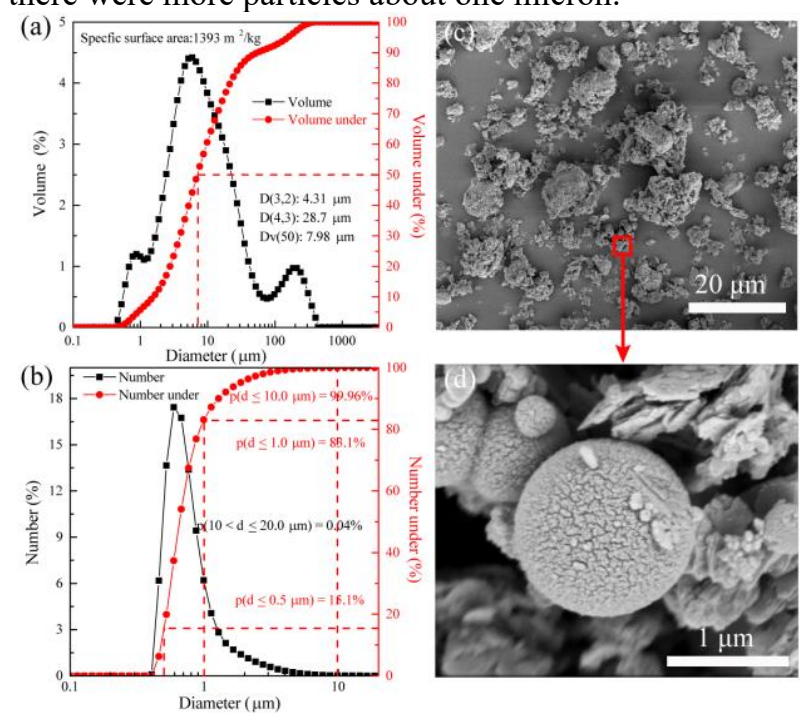


Fig. 2. Particle size distribution and SEM of solid particles in coal gasification wastewater. (a)(b) Particle size distribution;(c) (d) $\mathrm{S}$ canning electron micrograph

\subsection{Experimental procedure and test methods}

The particle size distribution was detected by British laser particle size analyzer Mastersizer 3000 (The measuring range is $0.01 \sim 3500 \mu \mathrm{m}$, the accuracy is better than $1 \%$ and the accuracy is better than $5 \%$ ). The solid particles in coal gasification wastewater were photographed by a high-resolution scanning electron microscope 250. The solid content of impurities in coal gasification wastewater was tested by the national standard drying method.

\subsection{Statistical analysis}

In the current work, the solid content $(N)$ was calculated as follows:

$$
N=\frac{\left(W_{1}-W_{0}\right)}{V}
$$

where $W_{l}$ is the weight of filter membrane, weighing dish and solid particles after drying, $\mathrm{mg} ; W_{0}$ is the weight of filter membrane and weighing dish after drying; $V$ is the volume of filtered coal gasification wastewater sample.

The separation efficiency $(\eta)$ was calculated as follows:

$$
\eta=\frac{\left(N_{\text {in }}-N_{\text {out }}\right)}{N_{\text {in }}} \times 100 \%
$$

where $N_{\text {in }}$ is the solid content of particles in the inlet coal gasification wastewater, $\mathrm{mg} / \mathrm{L} ; N_{\text {out }}$ is the solid content of particles in the sample coal gasification wastewater after separation, $\mathrm{mg} / \mathrm{L}$.

The solid content at one particle size $\left(N_{\mathrm{i}}\right)$ was calculated as follows:

$$
N_{i}=N_{\text {out }} \times f_{i}
$$

where $N_{\text {out }}$ is the solid content of particles in the sample coal gasification wastewater after separation, $\mathrm{mg} / \mathrm{L} ; f_{\mathrm{i}}$ is the ratio of the particle size $(i)$ distribution in the outlet coal gasification wastewater sample, $\%$.

The grading efficiency $\left(\eta_{i}\right)$ was calculated as follows:

$$
\eta_{i}=\frac{\left(N_{0}-N_{i}\right)}{N_{0}} \times 100 \%
$$

where $N_{0}$ is the solid content of particles in the inlet coal gasification wastewater, $\mathrm{mg} / \mathrm{L} ; N_{\mathrm{i}}$ is the solid content of at this particle in the sample liquid after separation, $\mathrm{mg} / \mathrm{L}$.

\section{Results and discussion}

As can be seen from Figure 3, the coal gasification wastewater was treated by sand filtration. With the increase of sand filtration separation bed, the solid content in the separated coal gasification wastewater gradually decreases, and its corresponding separation efficiency also shown an increasing trend[24]. When the inlet solid content was $7783 \mathrm{mg} / \mathrm{L}$, the bed was $1.9 \mathrm{~m}$, the solid content in the outlet coal gasification wastewater decreases to $4247 \mathrm{mg} / \mathrm{L}$, the separation efficiency was $45 \%$. When the separation bed was $3.8 \mathrm{~m}$, the solid content in the outlet wastewater was $3705 \mathrm{mg} / \mathrm{L}$, the separation efficiency was $52 \%$; When the separation bed was $4.75 \mathrm{~m}$, the solid content in the outlet wastewater was $2547 \mathrm{mg} / \mathrm{L}$, and the separation efficiency was $67 \%$; When the separation bed was $5.7 \mathrm{~m}$, the solid content in outlet wastewater was $832 \mathrm{mg} / \mathrm{L}$, the separation efficiency was $89 \%$. With the increase of separation bed, the solid content at outlet decreased greatly, the separation efficiency increased greatly. When the separation bed was $7.6 \mathrm{~m}$, the outlet solid content was $714 \mathrm{mg} / \mathrm{L}$, the separation efficiency was over $90 \%$. As the separation bed continued to increase to $11.4 \mathrm{~m}$, the outlet solid content decreased to $341 \mathrm{mg} / \mathrm{L}$, the separation efficiency was over $95 \%$.

It can be seen that when the separation bed increased, the removal of solid content in coal gasification wastewater increased obviously[21], but the increase was larger within $5.7 \mathrm{~m}$. The relative increase of separation efficiency was not as great as that of the former when it was 5.7-11.4 m. At the same time, it was proved that the increase of bed has a relatively suitable value.

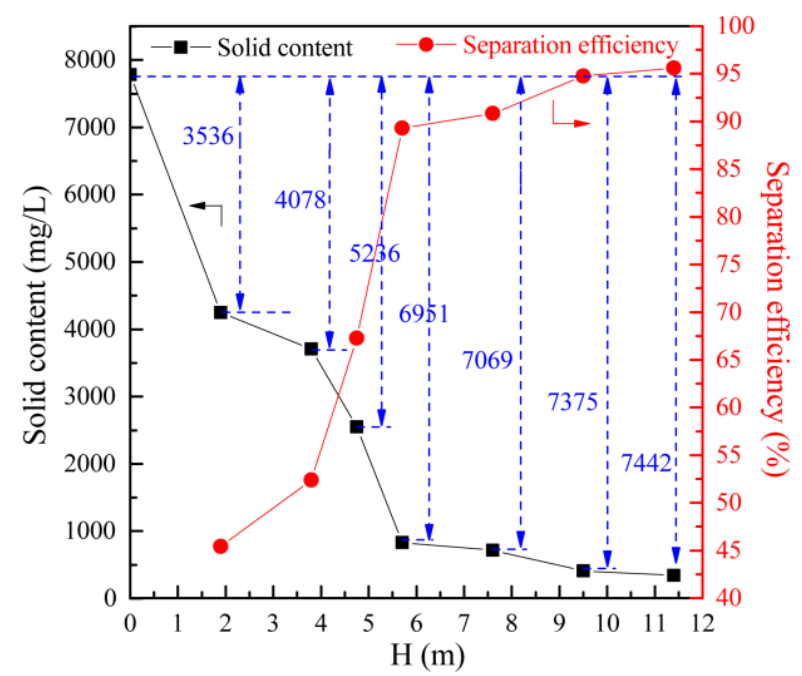

Fig. 3. The solid content and separation efficiency curve vary with the different beds.

The solid content curves of coal gasification wastewater samples at the inlet and after separation under different particle sizes were shown in Figure 4. It can be concluded that with the increase of separation bed, the solid content of coal gasification wastewater samples at different particle sizes tended to decrease[22], the solid content of particles larger than $100 \mu \mathrm{m}$ and smaller than $1 \mu \mathrm{m}$ was closed to zero.

When the separation bed was $1.9 \mathrm{~m}$, the particles below $0.76 \mu \mathrm{m}$ were completely removed, and with the increase of separation bed, the particles below $0.87 \mu \mathrm{m}$ were completely removed. Particles larger than $100 \mu \mathrm{m}$ were also completely removed. When the separation beds were $1.9 \mathrm{~m}, 3.8 \mathrm{~m}, 4.75 \mathrm{~m}, 5.7 \mathrm{~m}, 7.6 \mathrm{~m}, 9.5 \mathrm{~m}$ and 11.4 $\mathrm{m}$, the solid content of $0.46 \mu \mathrm{m} \sim 1 \mu \mathrm{m}$ decreased from $444 \mathrm{mg} / \mathrm{L}$ to $86 \mathrm{mg} / \mathrm{L}, 82 \mathrm{mg} / \mathrm{L}, 37 \mathrm{mg} / \mathrm{L}, 48 \mathrm{mg} / \mathrm{L}$ and 
$30 \mathrm{mg} / \mathrm{L}$. The solid content of $1 \mu \mathrm{m} \sim 10 \mu \mathrm{m}$ decreased from $4273 \mathrm{mg} / \mathrm{L}$ to below $2992 \mathrm{mg} / \mathrm{L}$, and the minimum was $1886 \mathrm{mg} / \mathrm{L}$. The solid content of $10 \mu \mathrm{m} \sim 40 \mu \mathrm{m}$ decreased from $2148 \mathrm{mg} / \mathrm{L}$ to below $1716 \mathrm{mg} / \mathrm{L}$, and the minimum was $1055 \mathrm{mg} / \mathrm{L}$. The solid content of 40 $\mu \mathrm{m} \sim 100 \mu \mathrm{m}$ decreased from $364 \mathrm{mg} / \mathrm{L}$ to below 281 $\mathrm{mg} / \mathrm{L}$, and the minimum was $4.6 \mathrm{mg} / \mathrm{l}$. Particles larger than $100 \mu \mathrm{m}$ were completely removed, and the solid content decreased from $553 \mathrm{mg} / \mathrm{L}$ to $0 \mathrm{mg} / \mathrm{L}$.

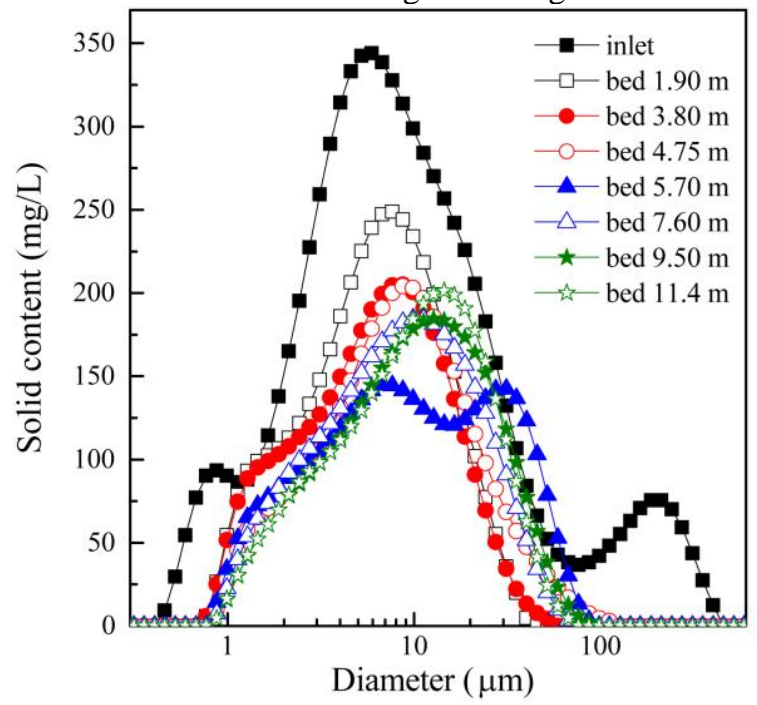

Fig. 4. The content corresponding to different particle sizes in coal gasification wastewater after separation of different beds.

The graded separation efficiency as shown in Figure 5, the separation bed height increases, and the graded efficiency increases. For the particles with particle size less than $1 \mu \mathrm{m}$ and larger than $100 \mu \mathrm{m}$, the curve changes of the graded efficiency in the separation bed tend to be consistent. The graded efficiency was more than $99 \%$ and tended to $100 \%$. When the particle size distribution was from $1 \mu \mathrm{m}$ to100 $\mu \mathrm{m}$, the graded efficiency gradually increased with the increase of bed thickness. When the separation bed was $1.9 \mathrm{~m}$, and the particle size was 1.5 $\mu \mathrm{m}$, the graded efficiency was lower than $5 \%$. The separation bed was increased to $3.8 \mathrm{~m}$, the graded efficiency increased from $20 \%$ to $32 \%$ at the particle size was $10 \mu \mathrm{m}$; The separation bed was $4.75 \mathrm{~m}$, the graded efficiency of particle size distribution from $1 \mu \mathrm{m}$ to 100 $\mu \mathrm{m}$ was greater than $50 \%$; When the bed was $5.7 \mathrm{~m}$, the grade efficiency of $20 \mu \mathrm{m}-70 \mu \mathrm{m}$ was larger than $65 \%$ and less than $85 \%$. The grade efficiency of $1 \mu \mathrm{m}-20 \mu \mathrm{m}$ and $70 \mu \mathrm{m}-100 \mu \mathrm{m}$ was larger than $80 \%$, then less than $90 \%$. When the separation bed was $7.6 \mathrm{~m}$, the grade efficiency of $1 \mu \mathrm{m}-100 \mu \mathrm{m}$ was greater than $85 \%$ and less than $95 \%$; When the separation bed was $9.5 \mathrm{~m}$, the grade efficiency of $1 \mu \mathrm{m}-100 \mu \mathrm{m}$ was greater than $90 \%$, and the maximum grade efficiency was $100 \%$; When the separation bed was $11.4 \mathrm{~m}$, the grade efficiency of $1 \mu \mathrm{m}$ $100 \mu \mathrm{m}$ was more than $92 \%$, and the maximum grade efficiency was $100 \%$.

The grade efficiency of particles smaller than $1 \mu \mathrm{m}$ was more than 99\%. According to the separation principle, the main separation mechanism for particles smaller than $1 \mu \mathrm{m}$ was diffusion[25]. However, small particles were more easy to adhere to the surface of the separation medium and deposit due to their electrostatic adsorption[24,26]. For the larger particle size larger than $100 \mu \mathrm{m}$, the removal was mainly due to the blocking[22] action of the separation medium. With the separation bed, the path of coal gasification wastewater passing through the separation bed increased, and the possibility of being blocked by the bed also increased[27]. Therefore, with the increase of separation bed, the grade efficiency of particle level tends to increase.

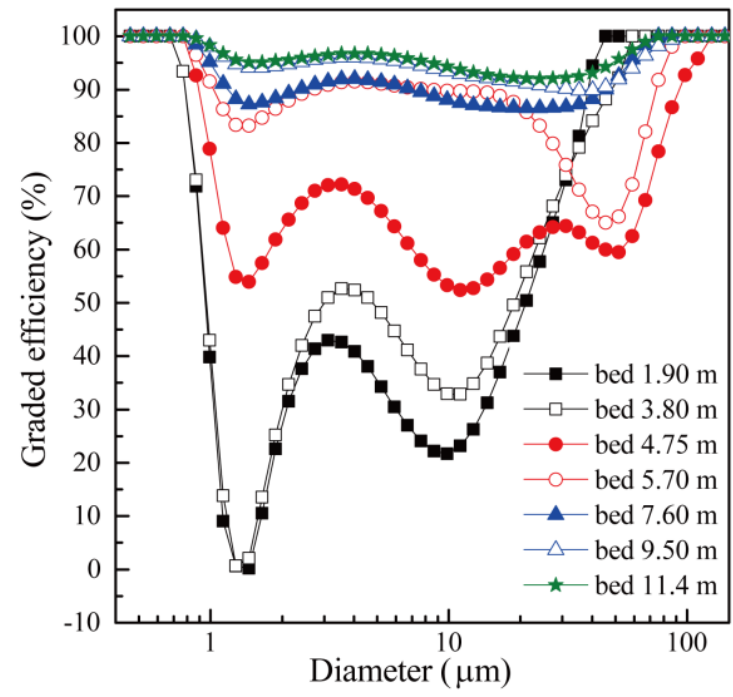

Fig. 5. The graded efficiency curve of solid particles in coal gasification wastewater by different beds.

\section{Conclusion}

In the present study, inspired by the mechanism of deep filtration and the removal of particulate pollutants from coal gasification wastewater, this study explored the feasibility experiment of removing insoluble particulate impurities from coal gasification wastewater by deep filtration with irregular quartz sand media. The removal performance of granular impurities in coal gasification wastewater by separation beds with different thicknesses was studied. The operation conditions were optimized for further industrial application and was of great significance for industrial application. Results suggested that:

With the sand filtration separation method, the fine particle pollutants in coal gasification wastewater can be effectively removed by more than $95 \%$, and the separation accuracy can reached $0.46 \mu \mathrm{m}$.

The particles below $0.76 \mu \mathrm{m}$ were completely removed, the solid content from $260 \mathrm{mg} / \mathrm{L}$ to $0 \mathrm{mg} / \mathrm{L}$. The separation efficiency was $100 \%$ and the grade separation efficiency also was $100 \%$; The solid content of larger than $100 \mu \mathrm{m}$ decreased from $553 \mathrm{mg} / \mathrm{L}$ to $0 \mathrm{mg} / \mathrm{L}$. the separation efficiency was $100 \%$ and the grade separation efficiency also was $100 \%$.

The solid content of $0.46 \mu \mathrm{m} \sim 1 \mu \mathrm{m}$ decreased from $444 \mathrm{mg} / \mathrm{L}$ to $30 \mathrm{mg} / \mathrm{L}$. The separation efficiency was greater than $80 \%$, the grade separation efficiency also was greater than $39 \%$; The solid content of $1 \mu \mathrm{m} \sim 10 \mu \mathrm{m}$ decreased from $4273 \mathrm{mg} / \mathrm{L}$ to below $2992 \mathrm{mg} / \mathrm{L}$, the separation efficiency was greater than $30 \%$, the grade 
separation efficiency also was greater than 10\%; The solid content of $10 \mu \mathrm{m} \sim 40 \mu \mathrm{m}$ decreased from $2148 \mathrm{mg} / \mathrm{L}$ to below $1716 \mathrm{mg} / \mathrm{L}$. the separation efficiency was greater than $23 \%$, the grade separation efficiency also was greater than $8 \%$; The solid content of $40 \mu \mathrm{m} \sim 100 \mu \mathrm{m}$ decreased from $364 \mathrm{mg} / \mathrm{L}$ to below $281 \mathrm{mg} / \mathrm{L}$. the separation efficiency was greater than $22 \%$, the grade separation efficiency also was greater than $14 \%$.

\section{Acknowledgment}

This work was supported by the sponsorship of National Key Research and Development Program of China (2019YFA0705800). The authors would like to express their appreciation for the support of the sponsors from paper 2020 8th International Conference on Environment Pollution and Prevention (ICEPP 2020) Sydney, Australia, December 3-5, 2020. Our gratitude also goes to the editor and anonymous reviewers who reviewed this paper.

\section{References}

1. $\mathrm{Ji}, \mathrm{Q}$. et al. A review on the coal gasification wastewater treatment technologies: past, present and future outlook. Journal of Cleaner Production 126, 38-55 (2016).

2. Chen, Z., Li, D. \& Wen, Q. Investigation of hydrolysis acidification process during anaerobic treatment of coal gasification wastewater (CGW): Evolution of dissolved organic matter and biotoxicity. The Science of the total environment 723, 137995 (2020).

3. Wang, Y. et al. Fate of potentially hazardous trace elements during the entrained-flow coal gasification processes in China. The Science of the total environment 668, 854-866 (2019).

4. Li, Y., Tabassum, S. \& Zhang, Z. An advanced anaerobic biofilter with effluent recirculation for phenol removal and methane production in treatment of coal gasification wastewater. J Environ Sci (China) 47, 23-33 (2016).

5. Fan, C., Lu, A., Li, Y. \& Wang, C. Pretreatment of actual high-strength phenolic wastewater by manganese oxide method. Chemical Engineering Journal 160, 20-26 (2010).

6. Riaz Qadeer, A. H. R. A study of the adsorption of phenol by activated carbon from aqueous solutions. Turkish Journal of Chemistry 26, 357-362 (2002).

7. Akcay, M. A., G. The removal of phenolic compounds from aqueous solutions by organophilic bentonite. J Hazard Mater 113, 189-193 (2004).

8. Palma, M. S. A., Paiva, J. L., Zilli, M. \& Converti, A. Batch phenol removal from methyl isobutyl ketone by liquid-liquid extraction with chemical reaction. Chemical Engineering and Processing: Process Intensification 46, 764-768 (2007).

9. Sheng $\mathrm{H}$ Lin, C. L. P., Hong G Leu. Liquid membrane extraction of 2-chlorophenol from aqueous solution. Journal of Hazardous Materials 65, 289304 (1999).
10. Sheng H Lin, C. S. W. Treatment of high-strength phenolic wastewater by a new two-step method. Journal of Hazardous Materials 90 (2002).

11. Li, P., Takahashi, M. \& Chiba, K. Degradation of phenol by the collapse of microbubbles. Chemosphere 75, 1371-1375 (2009).

12. Xu, A., Yang, M., Yao, H., Du, H. \& Sun, C. Rectorite as catalyst for wet air oxidation of phenol. Applied Clay Science 43, 435-438 (2009).

13. Qu, X., Zheng, J. \& Zhang, Y. Catalytic ozonation of phenolic wastewater with activated carbon fiber in a fluid bed reactor. J Colloid Interface Sci 309, 429434 (2007).

14. Vlasta Brezova, A. B., L' Karpinský, J Groskova, Bohuslava Havlinova, V Jorik, Michal Ceppan. Phenol decomposition using Mn+TiO2 photocatalysts supported by the sol-gel technique on glass fibres. Journal of Photochemistry and Photobiology A-chemistry 109, 177-183 (1997).

15. Kuo, C.-Y. L., Shang-Lien. Oxidation of aqueous chiorbiphenyls with photo-fenton process. Chemosphere 38, 2041-2051 (1999).

16. Li, K. et al. Application of nanofiltration model for prediction of rejecting typical refractory compounds in coal gasification brine. Desalination and Water Treatment 170, 46-54 (2019).

17. Li, K. et al. Selective recovery of salt from coal gasification brine by nanofiltration membranes. $J$ Environ Manage 223, 306-313 (2018).

18. WANG Hao-fei, L. Y.-w., LIU Kan. A process pilot for coal chemical wastewater treatment and crystalline salt separation. CHEMICAL ENGINEERING(CHINA) 47, 66-71 (2019).

19. Li, D. et al. Preparation and characterization of $\mathrm{SiO}$ /PDMS/PVDF composite membrane for phenols recovery from coal gasification wastewater in pervaporation. Chemical Engineering Research and Design 132, 424-435 (2018).

20. Sholl, D. S. \& Lively, R. P. Seven chemical separations to change the world. Nature 532, 435 (2016).

21. Dobre, T. et al. Species removal from aqueous radioactive waste by deep-bed filtration. Environmental pollution 241, 303-310 (2018).

22. ZAMANI, Amir \& MAINI. Flow of dispersed particles through porous media - Deep bed filtration. Journal of Petroleum Science \& Engineering 69, 7188 (2009).

23. Kirby, M. E. et al. Experimental study of $\mathrm{pH}$ effect on uranium (UVI) particle formation and transport through quartz sand in alkaline $0.1 \mathrm{M}$ sodium chloride solutions. Colloids and Surfaces A: Physicochemical and Engineering Aspects 592 (2020).

24. Kaetzl, K., Lubken, M., Nettmann, E., Krimmler, S. \& Wichern, M. Slow sand filtration of raw wastewater using biochar as an alternative filtration media. Sci Rep 10, 1229 (2020).

25. Kuzmina, L. I., Osipov, Y. V. \& Galaguz, Y. P. A model of two-velocity particles transport in a porous medium. International Journal of Non-Linear Mechanics 93, 1-6 (2017). 
26. Duan, L. et al. Rapid removal of low concentrations of mercury from wastewater using coal gasification slag. Korean Journal of Chemical Engineering 37, 1166-1173 (2020).

27. Michel, M. M. et al. Mineral Materials Coated with and Consisting of MnOx-Characteristics and Application of Filter Media for Groundwater Treatment: A Review. Materials (Basel) 13 (2020). 